\title{
Cervical cytological changes in HIV-infected patients attending care and treatment clinic at Muhimbili National Hospital, Dar es Salaam, Tanzania
}

\author{
Amos R Mwakigonja ${ }^{*}$, Liset Maria M Torres ${ }^{\dagger}$, Henry A Mwakyoma and Ephata E Kaaya
}

\begin{abstract}
Background: Tanzania is among Sub-Saharan countries mostly affected by the HIV and AIDS pandemic, females being more vulnerable than males. HIV infected women appear to have a higher rate of persistent infection by high risk types of human papillomavirus (HPV) strongly associated with high-grade squamous intraepithelial lesions (HSIL) and invasive cervical carcinoma. Furthermore, although HIV infection and cervical cancer are major public health problems, the frequency and HIV/HPV association of cervical cancer and HSIL is not well documented in Tanzania, thus limiting the development of preventive and therapeutic strategies.
\end{abstract}

Methods: A prospective unmatched, case-control study of HIV-seropositive, $\geq 18$ years of age and consenting nonpregnant patients attending the care and treatment center (CTC) at Muhimbili National Hoospital (MNH) as cases was done between 2005 and 2006. HIV seronegative, non-pregnant and consenting women recruited from the Cervical Cancer Screening unit (CCSU) at ORCI were used as controls while those who did not consent to study participation and/or individuals under $<18$ years were excluded. Pap smears were collected for routine cytodiagnosis and P53 immunohistochemistry (IHC). Cervical lesions were classified according to the Modified Bethesda System.

Results: A total of 170 participants from the two centers were recruited including $50 \mathrm{HIV}$-seronegative controls were from the CCSU. Ages ranged from 20-66 years (mean 40.5 years) for cases and 20-69 years (mean 41.6 years) for controls. The age group 36-45 years was the most affected by HIV $(39.2 \%, n=47)$. Cervicitis, squamous intraepithelial lesions (SIL) and carcinoma constituted 28.3\% $(n=34), 38.3 \%(n=46)$ and $5.8 \%(n=7)$ respectively among cases, and $28 \%(n=14), 34 \%(n=17)$ and $2 \%(n=1)$ for controls, although this was not statistically significant (P-value $=0.61)$. IHC showed that p53 was not detectable in HPV + Pap smears and cell blocks indicating possible degradation.

Conclusions: The frequency of SIL and carcinoma appeared to be higher among HIV-infected women on HAART compared to seronegative controls and as expected increased with age. HIV seropositive patients appeared to present earlier with SIL compared to those HIV seronegative suggesting a role of HIV in altering the natural history of HPV infection and cervical lesions. The absence of p53 immunoreactivity in HPV + lesions is indicative of the ability of HPV E6 proteins to interact with the tumor suppressor gene and pave way for viral-induced oncogenesis in the studied Tanzanian women.

\footnotetext{
* Correspondence: rodgeramos@yahoo.com

† Contributed equally

Department of Pathology, Muhimbili University of Health and Allied Sciences

(MUHAS), P.O. Box 65001, Dar es Salaam, Tanzania
} 


\section{Background}

Cancer of the uterine cervix remains the second commonest cancer among women worldwide [1], more than $85 \%$ of the global burden of this disease occurs in the developing world [1] being the commonest malignancy in women in Sub-Saharan Africa according to Globocan 2008 (IARC) [2]. The introduction of the Papanicolaou (Pap) smear in 1930's made early detection and treatment of pre-invasive disease possible, which has significantly reduced morbidity and mortality related to cervical cancer in developed but not developing countries, due to the absence of effective screening programs [3]. HIV-infected women have a higher likelihood of developing persistent high-risk human papillomavirus (HPV) infection, precancer [high-grade squamous intraepithelial lesions (HSIL)], and invasive cervical cancer than seronegative women but this has not been clearly documented in Tanzania $[1,4]$. Furthermore, HIV-associated cervical lesions are multicentric, aggressive and recurrent after treatment [5]. Co-infection with HPV and HIV is to be expected and recent epidemiological data from Africa show that cervical cancer is the most common AIDS defining neoplasm in women [5]. Among women infected with HIV there is a high prevalence of HPV infection [6]. Unlike other AIDS defining neoplasms, the occurrence of cervical cancer is not dependent on immune compromise [5]. It is established that invasive cervical cancer is the end result of progressive changes, beginning with precursor lesions namely cervical dysplasia or cervical intraepithelial neoplasia (CIN) also called squamous intraepithelial lesion (SIL), carcinoma in-situ (CIS) and lastly invasive carcinoma [7]. However, if early detection is made, pre-malignant lesions are reversible and cure of early-stage cancer is achievable. A number of risk factors that contribute to the development of cervical cancer, including low socioeconomic class, sexual intercourse at an early age, multiple sexual partners, multiparity, long-term oral contraceptive use, tobacco smoking, vitamin deficiency and sexually transmitted infection (STI) including Chlamydia trachomatis and Herpes virus type II have been identified [8-10] including the human papilloma virus (HPV) as a primary sexually transmitted etiologic agent in the development of cervical squamous cell carcinoma (CSCC) and its precursors [11]. Furthermore, HIV-related immunosuppression seems to contribute to increased frequency of SIL and HSIL as previously reported from Tanzania although that study did not include invasive cancer [12]. HIV infection and cervical cancer are major public health problems among women in Tanzania, although, the frequency of cervical cancer and pre-cancerous lesions in the general compared to the HIV-infected populations in Tanzania is not well documented and is elucidated in the current study.

\section{Methods}

\section{Study area}

The study was conducted in the Unit of Histopathology/ Morbid Anatomy as well as the Department Obstetrics/ Gynaecology at the Muhimbili National Hospital $(\mathrm{MNH})$, Dar es Salaam, Tanzania in collaboration with the Cervical Cancer Screening Unit (CCSU) at the Ocean Road Cancer Institute (ORCI).

\section{Study design and sampling criteria}

This was a prospective unmatched, case-control study of HIV-seropositive, $\geq 18$ years of age and consenting nonpregnant patients attending the care and treatment center (CTC) for highly active antiretroviral therapy (HAART) at MNH as cases was done between 2005 and 2006. HIV seronegative, non-pregnant and consenting women recruited from the Cervical Cancer Screening unit (CCSU) at ORCI were controls while those who did not consent to study participation and/or individuals under $<18$ years were excluded. Thus all women meeting these criteria at the two centres during the study period were included the sample prospectively.

\section{Laboratory methods HIV serology}

HIV-1 evaluation was done at the Department of Microbiology/Immunology, Muhimbili University of Health and Allied Sciences (MUHAS) and was performed on sera as previously described $[13,14]$ and results obtained through the medical records departments of $\mathrm{MNH}$ and ORCI.

\section{Pap smears}

Pap smears were performed by a Gynaecologist at the $\mathrm{MNH}$ and ORCI clinics. Patients were put in lithotomy position and a bivalve speculum was introduced. The cervix was exposed under illumination for assessment. Specimens were taken from the squamo-columnar junction using an Ayres spatula. The specimens were smeared on five SuperFrost ${ }^{\circledR}$ glass slides (Menzel GmbH \& Co KG, Braunschweigh, Germany) two of them fixed immediately in 95\% alcohol/ether for Papanicolaou staining (see below) and the rest air dried for two hours for immunocytochemistry. Slides were examined under a light microscope and cytodiagnosis done by a Pathologist.

\section{Papanicolau staining procedure}

Alcohol/ether-fixed smears were hydrated in graded alcohol as previously described [15] and stained with Harris Haematoxylin for 5 minutes, differentiated in 
$1.0 \%$ acetic acid in alcohol and blued in running tap water for 3 minutes. Smears were then dehydrated in ascending graded alcohol from $70 \%$ to $95 \%$ and stained with orange $\mathrm{G}$ for 3 minutes, rinsed in $95 \%$ alcohol followed by staining with EA 36 for three minutes and then dehydrated in absolute alcohol. Thereafter the smears were placed in xylene to remove alcohol and finally were mounted with DPX and glass cover slips were applied.

\section{Immunocytochemistry of acetone fixed smears}

The smears were fixed in cold acetone at $4^{\circ} \mathrm{C}$ for 10 minutes and dried at room temperature (RT) for 10 minutes. After Tris-Buffered Saline (TBS) rehydration, blocking of endogenous peroxidase activity with hydrogen peroxide ( $\mathrm{H} 2 \mathrm{O} 2)$ was done for 30 minutes at RT. Normal Horse Serum (NHS) diluted at 1:20 was then applied for 30 minutes at RT. The excess NHS was wiped off and slides incubated over night at $4{ }^{\circ} \mathrm{C}$ with primary antibodies [mouse monoclonal anti-human p53 (clone DO-7) (Dako, Glostrup, Denmark)]. After TBS washing slides were then processed and mounted as previously described $[15,16]$.

\section{Control of results}

Negative controls included sections which did not express the antigen under study and TBS instead of the primary antibody. Positive controls consisted of sections known to express the antigen under investigation.

\section{Immunohistochemistry on paraffin control sections}

This was done as previously described $[15,16]$. Five microns $(5 \mu)$ thick sections were placed in xylene over night for deparafinization, and hydrated in descending grades of ethanol to distilled water. Antigen retrieval was achieved by heating sections to boiling in Citrate Buffer at $\mathrm{pH} 6.0$ in a microwave oven for 10 minutes and sections then allowed to cool to RT. The remainder of the procedure was done as described above and previously $[15,16]$.

\section{Microscopy}

The smears were finally evaluated in a Carl Zeiss Axiomatic microscope (Jena, Germany) and digital microphotography was done using an Olympus Camera Model DP 12 (Olympus Corporation, Japan) and pictures processed using Adobe Photoshop 7.0 (Adobe Systems Incorporated, San Jose, USA).

\section{Data collection and management}

Patients' identification, biodata and experimental results were entered in structured and computer coded questionnaires.

\section{Data analysis}

Data analysis was done using computer package; EPI INFO 6 (CDC, Atlanta, Georgia, USA). P-values $\leq 0.05$ was considered statistically significant.

\section{Ethical issues}

Ethical permission was sought from the MUHAS Ethical Clearance Committee. Informed consent was sought from patients to screen them for HIV and for cervical cancer. Study participation/non-participation had no bearing whatsoever on the quantity and/or quality of the services the women expected to receive. All study information was processed in confidence and patients' IDs were never exposed.

\section{Study limitations}

a) Cytological changes suggestive of HPV infection may not reflect the true magnitude of HPV infection, since molecular techniques to detect HPV were not done due to logistical constrains.

b) Since only few cases were selected for p53 analysis, the conclusion may not reflect the true extent of p53 inactivation by HPV.

\section{Results}

\section{Demographic data of the patients}

A total of 170 women were recruited from the two centers (120 HIV-seropositive cases on HAART from MNH and 50 seronegative controls from ORCI) between 2005 and 2006. Singles constituted $64.1 \%(77 / 120)$ of cases and only $26 \%(13 / 50)$ of controls. The rest of women in each group were married which difference was highly statistically significant $(\mathrm{P}$-value $<0.001$ ), suggesting that singles were more likely to be HIV-infected (Figure 1 and Table 1). Age ranged from 20-66 years (mean 40.5

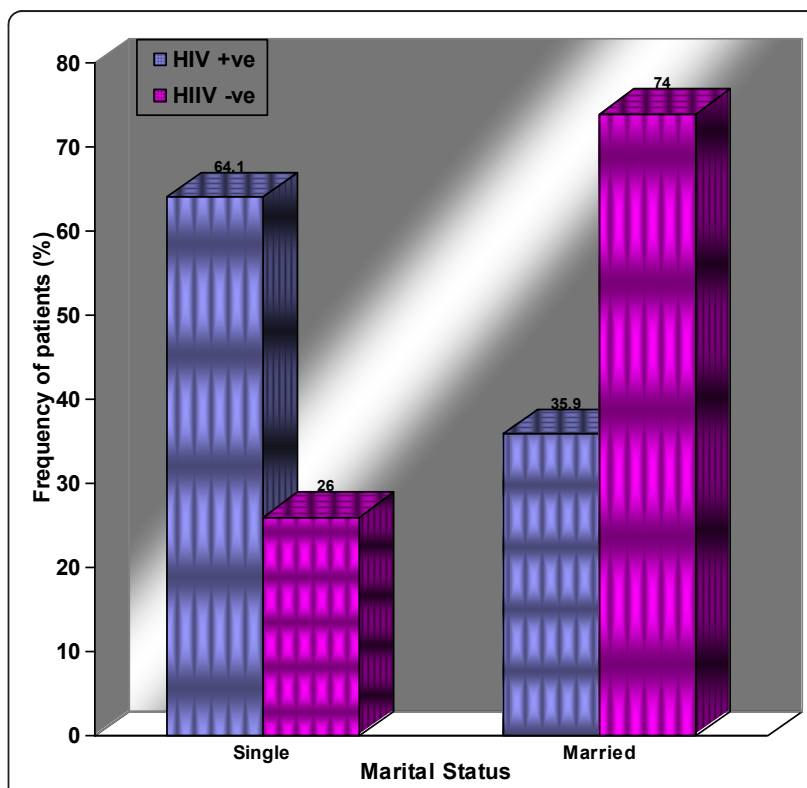

Figure 1 The distribution of patients according to marital status and HIV infection. Histograms showing the distribution of patients according to marital status and HIV infection. 
Table 1 List of the general characteristics of the studied Tanzanian women

\begin{tabular}{lrrrl}
\hline Characteristics & Cases & Controls & Combined & $\begin{array}{l}\text { P- } \\
\text { Value }\end{array}$ \\
\hline HIV serostatus & \multicolumn{7}{c}{} & & \\
Age-Range (years) & positive & negative & & \\
Mean Age (years) & $20-66$ & $20-69$ & $20-69$ & \\
Peak age-group (20-45years) & 40.5 & 41.6 & 41.05 & \\
[No (\%)] & 84 & $33(66.0)$ & $117(68.8)$ & 0.700 \\
Single [No (\%)] & $(70.0)$ & & & \\
& 77 & $13(26.0)$ & $90(52.9)$ & $<$ \\
Married [No (\%)] & $(64.1)$ & & & 0.001 \\
& 43 & $37(74.0)$ & $80(47.1)$ & $<$ \\
Total number & $(35.8)$ & & & 0.001 \\
\hline
\end{tabular}

This table shows that HIV infection was more frequent among singles compared to married women and as expected, majority of HIV seropositive women came from the most sexually active age-group of 20-45 years

years) among cases and from 20-69 years (mean 41.6 years) for Controls. The age group of 36-45 years was the most affected $(39.2 \%, 47 / 120)$ by HIV infection (Table 1).

\section{Distribution of cervical lesions}

Cervicitis, squamous intraepithelial lesions (SIL) and carcinoma constituted $28.3 \%$ (34/120), 38.3\% (46/120) and $5.8 \%(7 / 120)$ among cases, and $28 \%(14 / 50), 34 \%$ $(17 / 50)$ and $2 \%(1 / 50)$ for controls respectively, (P-value $=0.6)$ [Figure 2 and Table 2]. A great majority (94.1\%) of cases with cervicitis (32/34) had acute cervicitis [bacterial vaginosis (Figure 3 )] and only $2(5.9 \%)$ had chronic inflammation, and all HIV negative controls presented with acute cervicitis (Table 2). In this study $9.4 \%$ of smears of HIV infected patients with cervicitis showed some cells with cytoplasmic inclusions, suggesting

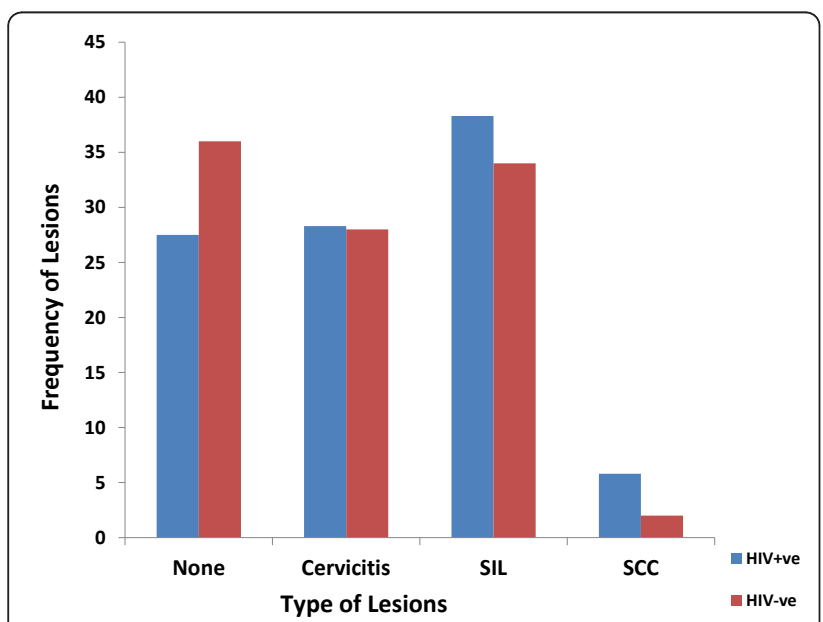

Figure 2 The distribution of cytological types of cervical carcinoma and HIV status. This Histogram shows that squamous cell carcinoma (SCC) as well as squamous intraepithelial lesions (SIL) were more common amongst HIV seropositive women.
Chlamydia infection (Figure 4). Furthermore, follicular cervicitis was identified in two conventional smears of HIV infected patients. A great majority (94.1\%) of cases with cervicitis (32/34) were single, while a lesser majority $(64.3 \%, 9 / 14)$ HIV negative controls were single (Pvalue $=0.02)$, indicating that HIV infected patients on HAART who are single were at an increased risk for cervicitis compared with corresponding controls. The same applied to the association of SIL and cervical cancer with marital status, number of sexual partners and increased parity but not with the use of oral contraceptives (OC) were majority of cases and controls with the conditions were non-OC users.

Majority $(58.6 \%, 27 / 46)$ of SIL were LSIL (Figure 5) and the rest were HSIL (Figure 6). However, a greater majority (76.4\%) of HIV negative controls had LSIL (13/ 17) $(\mathrm{P}$-value $=0.25)$ [Table 2]. Binucleated cells suggestive of HPV or TV infections were present on 18.5\% (5/ 27) smears of HIV infected patients on HAART and 7.7\% (1/13) smears of HIV negative control (Figure 5). A great majority $(85.7 \%, 6 / 7)$ of cases with carcinoma had squamous cell carcinoma (SCC) but 1 (14.3\%) had adenocarcinoma (AC) [Figure 7]. Only one patient with cervical malignancy amongst controls had SCC. Orangeophilic cells suggestive of keratinization, were found in $66.6 \%(4 / 6)$ cases (Figure 7). The distribution of cytological features suggestive of HPV infection (koilocytosis) between cases and controls was not statistically significant $(\mathrm{P}$-value $=0.76)$. However, this was more frequent $(77.8 \%, 21 / 27)$ in smears of cases older than 35 years but less so $(55.6 \%, 5 / 9)$ of smears from controls. Furthermore, a great majority $(96.3 \%, 26 / 27)$ of cases with cervical koilocytosis had had first sexual intercourse before age 17 years but less so $(77.8 \%, 7 / 9)$, among controls $(\mathrm{P}$-value $=0.02)$. This implies that an early age of sexual debut increases the risk to HIV, HPV and/or other STI.

\section{Immunohistochemistry}

This was performed on cell blocks and smears from the cervix fixed in cold acetone for 13 cases of LSIL, 7 cases of HSIL and 4 cases of carcinoma with cytomorphological features suggestive of HPV infection. The expression of p53 was absent in the tested slides compared with the colorectal carcinoma used as positive control, in which the expression of p53 was strong and nuclear in location. These results suggest the ability of HPV oncogenes (like E6) to interact with p53 although the samples tested were few.

\section{Discussion}

The increased frequency of cervical lesions generally among adults in this study contrasted those of a previous study reporting a peak among adolescents and 
Table 2 Distribution of cervicitis and SIL according to HIV serostatus

\begin{tabular}{|c|c|c|c|c|c|c|c|c|c|}
\hline $\begin{array}{l}\text { HIV } \\
\text { status }\end{array}$ & $\begin{array}{l}\text { LSIL } \\
\text { No (\%) }\end{array}$ & $\begin{array}{c}\text { HSIL } \\
\text { No } \\
\text { (\%) }\end{array}$ & $\begin{array}{c}\text { Total SIL No } \\
\text { (\%) }\end{array}$ & $\begin{array}{c}P \text { - } \\
\text { Values }\end{array}$ & $\begin{array}{c}\text { Acute Cervicitis No } \\
\text { (\%) }\end{array}$ & $\begin{array}{c}\text { Chronic Cervicitis No } \\
\text { (\%) }\end{array}$ & $\begin{array}{c}\text { Total Cervicitis No } \\
\text { (\%) }\end{array}$ & $\begin{array}{l}\text { Total Cervical } \\
\text { Lesions }\end{array}$ & $\begin{array}{c}P \text { - } \\
\text { Values }\end{array}$ \\
\hline HIV +ve & $27(58.6)$ & $\begin{array}{c}19 \\
(41.3)\end{array}$ & $46(38.3)$ & 0.25 & $32(94.1)$ & 2(5.9) & $34(28.3)$ & $80(66.7)$ & $\begin{array}{l}P= \\
0.61\end{array}$ \\
\hline HIV -ve & $13(76,4)$ & $4(23.5)$ & $17(34.0)$ & 0.25 & $14(100.0)$ & $0(0.0)$ & $14(28.0)$ & $31(62.0)$ & $\begin{array}{l}P= \\
0.61\end{array}$ \\
\hline Total & $\begin{array}{c}40 \\
(63.5)\end{array}$ & $\begin{array}{c}23 \\
(36.5)\end{array}$ & $63(56.8)$ & 0.25 & $46(95.8)$ & $2(4.2)$ & $48(43.2)$ & $111(100.0)$ & $\begin{array}{l}P= \\
0.61\end{array}$ \\
\hline
\end{tabular}

This table shows that the distribution of cervicitis did not vary with HIV serostatus and the distribution of HSIL appeared more likely to vary with HIV serostatus compared to LSIL although both were not statistically significant

young adults [17]. However, the discrepancy in the results could be due to selection bias considering that all our patients were recruited from the CTC, which is mainly attended by patients older than 25 years on ART and hence not representative of the general population.

In the present study the frequency of cervicitis among HIV infected patients appears higher compared to a US study where it was reported to be $15 \%$ [18]. The difference may be due to the higher prevalence of HIV and AIDS in sub-Saharan Africa (including Tanzania) compared to USA $[19,20]$.

That the HIV seropositive patients on HAART (cases) were more likely to have SIL and invasive carcinoma of the cervix than their corresponding controls seems in part, to be related the increased risk behavior for STI including HPV, HSV and in fact HIV among this group as depicted by marital status (singles), number of lifetime sexual partners (multiple) and an early age at first sexual intercourse [21-23]. A previous study showed that inflammatory changes on cervical cytological smears often indicate the presence of STI and masked underlying premalignant disease of the cervix [24].

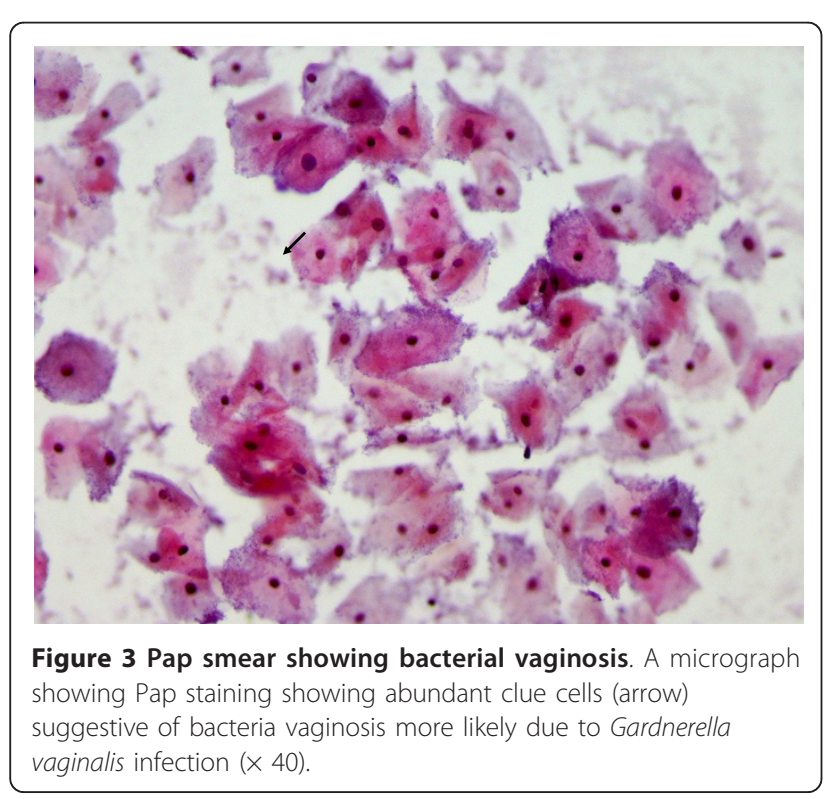

Due to limitations in resources, the isolation of Chlamydia in cell culture as well as the use of monoclonal antibody to detect Chlamydia elementary bodies could not be achieved in the current study. Nevertheless, our index study indicated that features suggestive of Chlamydia cervicitis were more common among HIV infected patients, which corroborates with several previous reports in which researchers reported that the highest prevalence of Chlamydia trachomatis (CT) there was found in HIV infected individuals $[25,26]$. CT is the most common cause of STI and cytological changes in Pap smears documented [25]. However, a previous study reported that some Chlamydia negative patients had a Pap test which was reported to contain inclusions consistent with Chlamydia infection [27]. The author speculated that the inclusions were probable aggregates of bacteria, cell debris and/or other artifacts thus concluding that the Pap test has low sensitivity compared to Chlamydia culture. Furthermore, follicular cervicitis (FC) also identified in this study is reported to be associated with CT infection [28].

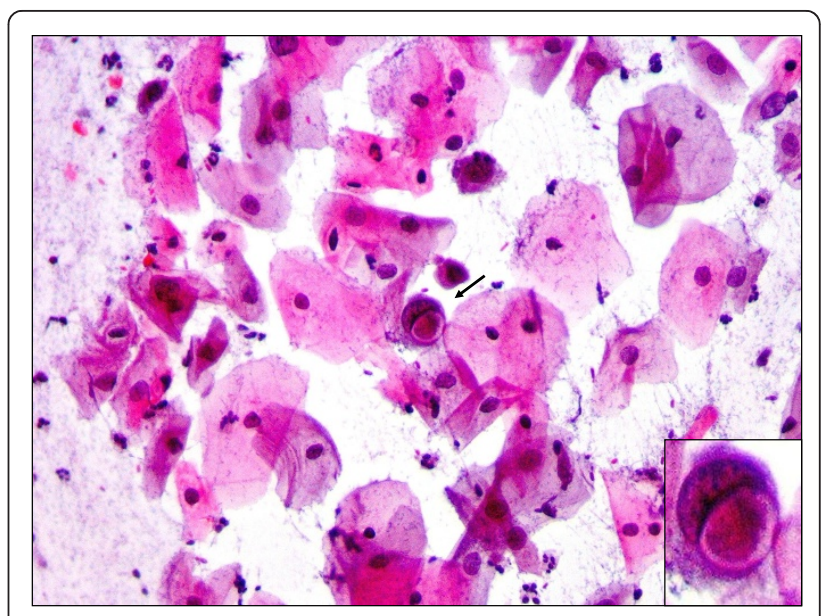

Figure 4 Pap smear showing Chlamydia cervicitis. Pap staining in a patient with acute cervicitis showing a squamous cell with cytopathic changes characterized by the presence of a cytoplasmic inclusion body (arrow and inset) indicating Chlamydia infection $(x$ 40). 


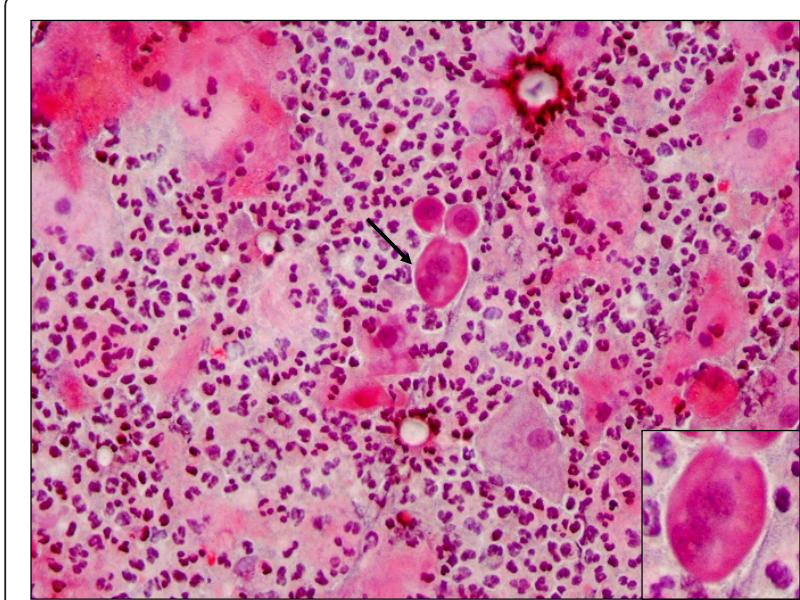

Figure 5 Pap smear showing LSIL. Pap staining in a patient with LSIL showing extensive leukocytic background and a binucleated parabasal squamous cell with mild nuclear enlargement and fine granular chromatin (arrow and inset) suggestive of viral (HPV) or TV infection $(\times 100)$.

Squamous cell carcinoma was the most predominant type of cancer found among HIV infected patients which would be consistent with a concurrent HPV infection as suggested in our results and would be in agreement with a previous report indicating that HIV alters the natural history of HPV infection, with decreased regression rates and more rapid progression to high grade and invasive lesions, which are refractory to treatment, requiring more stringent intervention and monitoring [5]. However, a previous report suggested a high frequency of adenocarcinoma amongst HIV-

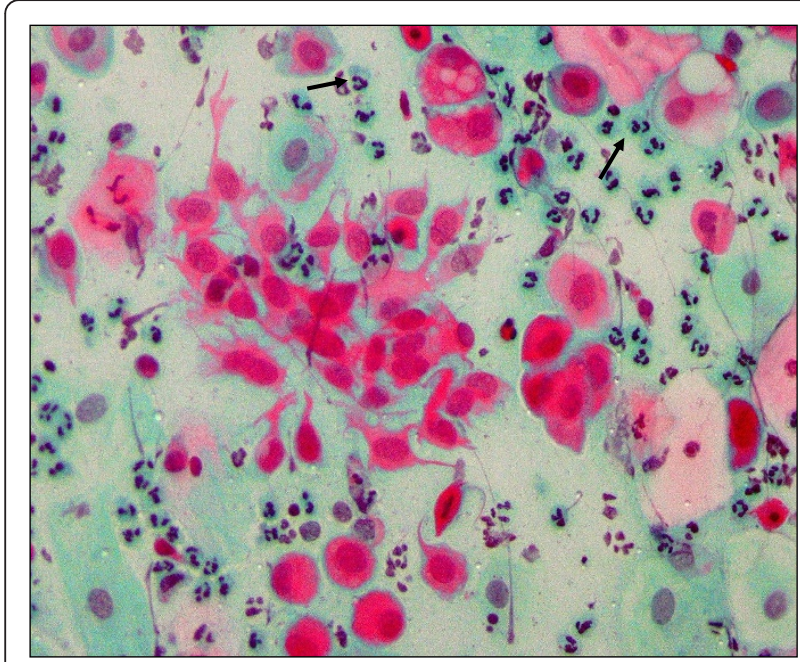

Figure 6 Pap smear showing HSIL. Pap staining in a patient with HSIL showing abundant neutrophils, a cluster of dendritic cells. The arrows show a parabasal squamous cell with multiple cytoplasmic vacuolation suggestive of viral infection $(\times 40)$.

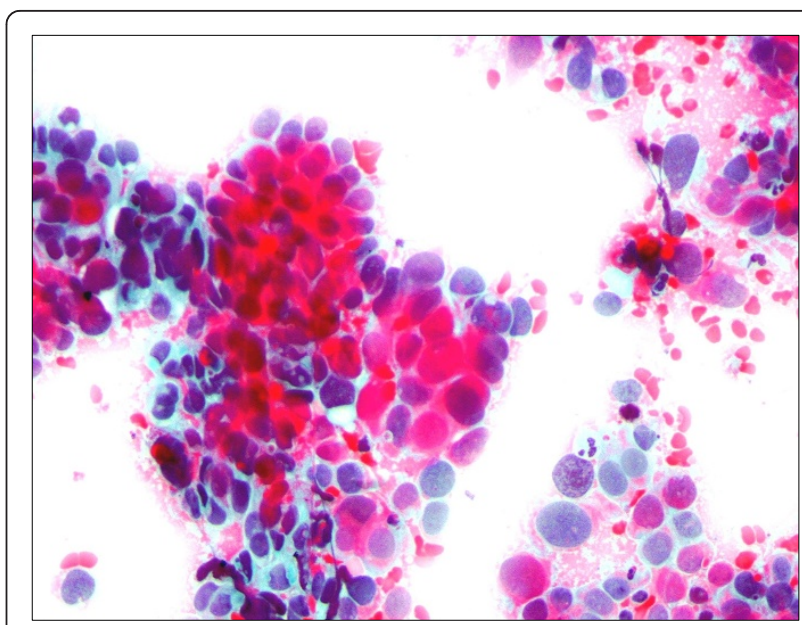

Figure 7 Pap smear showing cervical cancer. Pap staining in a patient with squamous carcinoma which exhibits clusters of cohesive cells with marked nuclear enlargement, pleomorphisms, hyperchromatism and keratinization $(\times 40)$.

infected patients [29] and epidemiological and sample population differences may explain the discrepancy. However, both the current and the previous studies report increasing frequency of amongst those aged $\geq 56$ years as expected [29]. Cervical cancer in women younger than 25 years is extremely rare [10]. HIV infected women with cervical cancer before the age 35 years is considered an acquired AIDS-defining illness by the Centers for Diseases Control (CDC) [5,30,31].

The relationship between high parity, OC use and cervical cancer has been suggested and is probably attributed to hormonal factors $[29,32]$.

Loss of wild-type p53 activity is an important event in neoplastic transformation in cervical squamous epithelium and is thought to occur by its degradation by the E6 viral protein of HPV 16 and HPV 18 [33]. On the basis of these mechanisms, clinically relevant p53 immunoreactivity would not be expected in HPV related cervical carcinoma and SIL and this is shown in our current study which also concurs with previous reports suggesting that the expression of p53 is decreased in lesions infected with intermediate and high risk HPV due to the differential ability of HPV E6 proteins to bind to and degrade p53 [33,34]. Thus the frequency, distribution, risk factors and pathogenesis of cervical lesions amongst a selected cohort of Tanzanian women, have been further elucidated by our current study.

\section{Conclusions}

The cytological findings in this study suggest that the frequency of SIL and carcinoma appeared to be higher among HIV-infected women on HAART compared to seronegative controls and as expected increased with 
age. HIV seropositive patients appeared to present earlier with SIL compared to those HIV seronegative suggesting a role of HIV in altering the natural history of HPV infection and cervical lesions. The absence of p53 immunoreactivity in HPV + lesions is indicative of the ability of HPV E6 proteins to interact with the tumor suppressor gene and pave way for viral-induced oncogenesis in the studied Tanzanian women.

\section{Acknowledgements}

We greatly appreciate the technical assistance of Mr. Onjection Byobangamba and the late Miss Ruth Wejja. Furthermore, we are very grateful for the financial support from the Ministry of Health and Social Welfare (MoHSW) of the United Republic of Tanzania as well as the then TANSWED PROJECT E under Sida/SAREC (Sweden) collaborative research which provided reagents. We are also grateful to the Heads and members of the Departments of Pathology (MUHAS) as well as Laboratory Services $(\mathrm{MNH})$ where the study was conducted.

\section{Authors' contributions}

LMM conceived the study, collected tissue specimen, clinical records, and performed the staining, data analysis as well as contributed to manuscript writing. ARM conceived the study, supervised proposal write-up, taught, performed and supervised the staining, performed microphotography, supervised data analysis, wrote the manuscript, corresponded with editors and publishers and effected all reviewers' and editorial corrections. HAM conceived the study, supervised proposal write-up and data analysis and corrected the manuscript. EEK conceived and supervised the study, procured reagents, taught and supervised the staining and corrected the manuscript. All authors read and approved the final manuscript.

\section{Competing interests}

The authors declare that they have no competing interests.

Received: 30 October 2011 Accepted: 15 February 2012 Published: 15 February 2012

\section{References}

1. Chibwesha CJ, Cu-Uvin S: See-and-treat approaches to cervical cancer prevention for HIV-infected women. Curr HIV/AIDS Rep 2011, 8(3):192-199.

2. Ferlay J, Shin HR, Bray F, Forman D, Mathers C, Parkin DM: Estimates of worldwide burden of cancer in 2008: GLOBOCAN 2008. Int I Cancer 2010, 127(12):2893-2917.

3. Sun XW, Kuhn L, Ellerbrock TV, Chiasson MA, Bush TJ, Wright TC Jr: Human papillomavirus infection in women infected with the human immunodeficiency virus. N Engl J Med 1997, 337(19):1343-1349.

4. Spitzer M: Cervical screening adjuncts: recent advances. Am J Obstet Gynecol 1998, 179(2):544-556.

5. Clarke B, Chetty R: Postmodern cancer: the role of human immunodeficiency virus in uterine cervical cancer. Mol Pathol 2002, 55(1):19-24.

6. ter Meulen J, Eberhardt HC, Luande J, Mgaya HN, Chang-Claude J, Mtiro H, Mhina M, Kashaija P, Ockert S, Yu X, et al: Human papillomavirus (HPV) infection, HIV infection and cervical cancer in Tanzania, east Africa. Int J Cancer 1992, 51(4):515-521.

7. Liaw KL, Hsing AW, Chen CJ, Schiffman MH, Zhang TY, Hsieh CY, Greer CE, You SL, Huang TW, Wu TC, et al: Human papillomavirus and cervical neoplasia: a case-control study in Taiwan. Int J Cancer 1995, 62(5):565-571.

8. Coker AL, Hulka BS, McCann MF, Walton LA: Barrier methods of contraception and cervical intraepithelial neoplasia. Contraception 1992, 45(1):1-10.

9. Hildesheim A, Brinton LA, Mallin K, Lehman HF, Stolley P, Savitz DA, Levine R: Barrier and spermicidal contraceptive methods and risk of invasive cervical cancer. Epidemiology 1990, 1(4):266-272.

10. Schiffman MH: New epidemiology of human papillomavirus infection and cervical neoplasia. J Natl Canc Inst 1995, 87(18):1345-1347.
11. Ley C, Bauer HM, Reingold A, Schiffman MH, Chambers JC, Tashiro CJ, Manos MM: Determinants of genital human papillomavirus infection in young women. J Natl Canc Inst 1991, 83(14):997-1003.

12. Kapiga SH, Msamanga Gl, Spiegelman D, Mwakyoma H, Fawzi WW, Hunter DJ: Risk factors for cervical squamous intraepithelial lesions among HIV-1 seropositive women in Dar es Salaam, Tanzania. Int J Gynaecol Obstet 1999, 67(2):87-94.

13. Urassa WK, Kaaya EE, Kitinya JN, Lema LL, Amir H, Luande J, Biberfeld G, Mhalu FS, Biberfeld P: Immunological profile of endemic and epidemic Kaposi's sarcoma patients in Dar-es-Salaam, Tanzania. Int J Mol Med 1998, 1(6):979-982

14. Urassa WK, Mbena EM, Swai AB, Gaines H, Mhalu FS, Biberfeld G: Lymphocyte subset enumeration in HIV seronegative and HIV-1 seropositive adults in Dar es Salaam, Tanzania: determination of reference values in males and females and comparison of two flow cytometric methods. J Immunol Methods 2003, 277(1-2):65-74.

15. Pyakurel P, Pak F, Mwakigonja AR, Kaaya E, Biberfeld P: KSHV/HHV-8 and HIV infection in Kaposi's sarcoma development. Infect Agent Cancer 2007, 2:4.

16. Pyakurel P, Pak F, Mwakigonja AR, Kaaya E, Heiden T, Biberfeld P: Lymphatic and vascular origin of Kaposi's sarcoma spindle cells during tumor development. Int J Cancer 2006, 119(6):1262-1267.

17. Kelly BA, Black AS: The inflammatory cervical smear: a study in general practice. Br J Gen Pract 1990, 40(335):238-240.

18. Marrazzo JM, Wiesenfeld HC, Murray PJ, Busse B, Meyn L, Krohn M, Hillier SL: Risk factors for cervicitis among women with bacterial vaginosis. J Infect Dis 2006, 193(5):617-624.

19. Kopelman LM, van Niekerk AA: AIDS and Africa. Introduction. J Med Philos 2002, 27(2):139-142.

20. Parsons WL, Godwin M, Robbins C, Butler R: Prevalence of cervical pathogens in women with and without inflammatory changes on smear testing. BMJ 1993, 306(6886):1173-1174.

21. Ellerbrock TV, Chiasson MA, Bush TJ, Sun XW, Sawo D, Brudney K, Wright TC $\mathrm{Jr}$ : Incidence of cervical squamous intraepithelial lesions in HIV-infected women. Jama 2000, 283(8):1031-1037.

22. Ho GY, Burk RD, Klein S, Kadish AS, Chang CJ, Palan P, Basu J, Tachezy R, Lewis $R$, Romney $S$ : Persistent genital human papillomavirus infection as a risk factor for persistent cervical dysplasia. Journal of the National Cancer Institute 1995, 87(18):1365-1371.

23. Richart RM, Barron BA: A follow-up study of patients with cervical dysplasia. Am J Obstet Gynecol 1969, 105(3):386-393.

24. Wilson JD, Robinson AJ, Kinghorn SA, Hicks DA: Implications of inflammatory changes on cervical cytology. BMJ 1990, 300(6725):638-640.

25. Msuya SE, Mbizvo E, Stray-Pedersen B, Sundby J, Sam NE, Hussain A: Reproductive tract infections and the risk of HIV among women in Moshi, Tanzania. Acta Obstet Gynecol Scand 2002, 81(9):886-893.

26. Marte C, Kelly P, Cohen M, Fruchter RG, Sedlis A, Gallo L, Ray V, Webber CA Papanicolaou smear abnormalities in ambulatory care sites for women infected with the human immunodeficiency virus. Am J Obstet Gynecol 1992, 166(4):1232-1237.

27. Forster GE, Cookey I, Munday PE, Richman PI, Jha R, Coleman D, Thomas BJ, Hawkins DA, Evans RT, Taylor-Robinson D: Investigation into the value of Papanicolaou stained cervical smears for the diagnosis of chlamydial cervical infection. J Clin Pathol 1985, 38(4):399-402.

28. Halford JA: Cytological features of chronic follicular cervicitis in liquidbased specimens: a potential diagnostic pitfall. Cytopathology 2002, 13(6):364-370.

29. Bosch FX: Trends in cervical cancer mortality. J Epidemiol Commun Health 1999, 53(7):392.

30. Maiman M, Fruchter RG, Clark M, Arrastia CD, Matthews R, Gates EJ: Cervical cancer as an AIDS-defining illness. Obstet Gynecol 1997, 89(1):76-80.

31. Serraino D, Dal Maso L, La Vecchia C, Franceschi S: Invasive cervical cancer as an AIDS-defining illness in Europe. AIDS (London, England) 2002, 16(5):781-786.

32. Schuman P, Ohmit SE, Klein RS, Duerr A, Cu-Uvin S, Jamieson DJ, Anderson J, Shah KV: Longitudinal study of cervical squamous intraepithelial lesions in human immunodeficiency virus (HIV)seropositive and at-risk HIV-seronegative women. J Infect Dis 2003, 188(1):128-136. 
33. Jeffers MD, Richmond J, Farquharson M, McNicol AM: p53

immunoreactivity in cervical intraepithelial neoplasia and non-neoplastic cervical squamous epithelium. J Clin Pathol 1994, 47(12):1073-1076.

34. Werness BA, Wang HQ, Chance J, Goldstein DJ: p53-independent expression of p21waf1/cip1 in preinvasive and invasive squamous neoplasms of the uterine cervix. Mod Pathol 1997, 10(6):578-584.

doi:10.1186/1750-9378-7-3

Cite this article as: Mwakigonja et al: Cervical cytological changes in HIV-infected patients attending care and treatment clinic at Muhimbili National Hospital, Dar es Salaam, Tanzania. Infectious Agents and Cancer 2012 7:3.

Submit your next manuscript to BioMed Central and take full advantage of:

- Convenient online submission

- Thorough peer review

- No space constraints or color figure charges

- Immediate publication on acceptance

- Inclusion in PubMed, CAS, Scopus and Google Scholar

- Research which is freely available for redistribution

Submit your manuscript at www.biomedcentral.com/submit 